\title{
Breathing pattern, ventilatory drive and respiratory muscle strength in patients with chronic heart failure
}

\author{
N. Ambrosino*, C. Opasich**, P. Crotti*, F. Cobelli**, L. Tavazzi**, C. Rampulla*
}

\begin{abstract}
Breathing pattern, ventilatory drive and respiratory muscle strength in patients with chronic heart failure. N. Ambrosino, C. Opasich, P. Crotti, F. Cobelli, L. Tavazzi, C. Rampulla. OERS Journals Ltd 1994.
\end{abstract}

ABSTRACT: The purpose of this study was to evaluate whether chronic heart failure (CHF) may induce changes in breathing pattern and ventilatory neural drive.

We studied 45 male inpatients with CHF, (25 patients in NYHA class II, 20 in class III) and 22 sex-matched post myocardial infarction patients without left ventricular dysfunction who served as controls. CHF patients underwent right heart catheterization and assessment of cardiac output by thermodilution technique. Patients and controls underwent evaluation of left ventricular ejection fraction by 2D echocardiography, spirometry, diffusion capacity, blood gases, breathing pattern, mouth occlusion pressure and respiratory muscle strength determination. Results of $\mathrm{CHF}$ patients were compared to controls and evaluated for differences according to the degree in severity of functional impairment.

CHF patients showed a slight reduction in lung volumes and in diffusion capacity. In CHF neural drive, as assessed by mouth occlusion pressure $\left(P_{0,1}\right)$, was significantly increased in comparison to controls $\left(\mathrm{P}_{0.1}=1.86(0.7)\right.$ and $1.4(0.6) \mathrm{cmH}_{2} \mathrm{O}$ in $\mathrm{CHF}$ and controls respectively). Analysis of breathing pattern showed only a slight yet significant increase in respiratory frequency while respiratory muscle strength, as assessed by measurement of maximal inspiratory and expiratory pressures (MIP and MEP respectively) was slightly reduced $(\mathrm{MIP}=79(27)$ and $104(28)$; $M E P=111(32)$ and 142(33) $\mathrm{cmH}_{2} \mathrm{O}$ respectively). Observed changes were more relevant in patients with advanced NYHA functional classes whereas no relationship among indices of cardiac and respiratory function was found.

We conclude that chronic heart failure induces changes in neural ventilatory drive and respiratory muscle strength related to the severity of the disease.

Eur Respir J., 1994, 7, 17-22.

Published studies on pulmonary function in patients with chronic heart failure (CHF) show both obstructive and restrictive abnormalities, combined or not with diffusion impairment [1-4]. A selective reduction in respiratory muscle strength has been also observed in a relatively small number of CHF patients [5]. The mechanism for diffusion impairment has been suggested to be chronic passive congestion with pulmonary fibrosis and/or recurrent pulmonary emboli. Reduction in respiratory muscle blood flow or generalized muscular atrophy and weakness related to cardiac cachexia have been proposed as possible explanations for reduction in respiratory muscle strength [5].

The aim of this study was to evaluate whether such $\mathrm{CHF}$ related conditions might lead also to changes in breathing pattern and neural respiratory drive, which to our knowledge has not been extensively studied in CHF patients. To investigate this hypothesis we evaluated breathing pattern, ventilatory drive and respiratory muscle strength in patients with $\mathrm{CHF}$ and compared their results with measurements performed in uncomplicated post recent myocardial infarction patients. Furthermore we examined the relationship between the respiratory findings and the degree of severity of patient functional impairment.
*Pulmonary and **Cardiac Divisions, Fondazione Clinica IRCCS, Centro Medico di Riabilitazione di Montescano, Pavia, Italy.

Correspondence: N. Ambrosino

Divisione di Pneumologia

Centro Medico di Riabilitazione di Montescano

27040 Montescano

Pavia

Italy

Keywords: Congestive heart failure heart transplantation respiratory muscles ventilatory drive ventilatory pattern

Received: January 121993 Accepted after revision July 201993
Materials and methods

\section{Patients}

Forty five male inpatients with $\mathrm{CHF}$, referred to our institution for evaluation of suitability for heart transplantation, were studied when in stable state. The aetiology of heart failure was coronary artery disease in 30 patients, primary cardiomyopathy in 13 and valvular disease in 2 . Left ventricular ejection fraction (LVEF) was $<40 \%$ in all.

Eight patients were current smokers, 35 were former smokers (cessation since 3 months to 40 years), 2 had never smoked. Chest roentgenographic abnormalities attributable to pulmonary vascular congestion were found in 36 out of $45 \mathrm{CHF}$ patients (redistribution of pulmonary blood flow (9 patients), pleural effusions (8 patients), widened vascular pedicle (31 patients), alone or in combination). No patient showed roentgenographic signs of diaphragmatic dysfunction. All patients were on stable conventional medical therapy and none had a clinical history of lung disease, nor recent respiratory infection. Twenty five were judged as being in New York Heart Association (NYHA) class II, and 20 as being in NYHA class III [6] 
Table 1. - Demographic and cardiac function data

\begin{tabular}{lcccc}
\hline & & \multicolumn{3}{c}{ CHF } \\
\cline { 3 - 5 } & Control & All & NYHA II & NYHA III \\
\hline Patients n & 22 & 45 & 25 & 20 \\
Age yr & $51(7)$ & $54(8)$ & $51(8) \dagger$ & $56(7)$ \\
Weight Kg & $76(11)$ & $69(10)^{*}$ & $71(11)$ & $68(10)$ \\
Height cm & $171(6)$ & $171(6)$ & $170(60)$ & $171(6)$ \\
Duration months & - & $37(30)$ & $33(24)$ & $43(36)$ \\
LVEF \% & $56(6)$ & $22(7)^{*}$ & $23(7)$ & $20(7)$ \\
CI l-min ${ }^{-1} \cdot \mathrm{m}^{-2}$ & & $2.1(0.4)$ & $2.1(0.4)$ & $2.1(0.4)$ \\
PCWP kPa & & $2.63(1.1)$ & $2.36(1.1)$ & $3.02(1.1)$
\end{tabular}

Mean (SD). *: significant difference $(\mathrm{p}<0.05)$ between all CHF and Controls; + : significant difference between NYHA Classes $(p<0.05)$; CHF: chronic heart failure; LVEF: left ventricular ejection fraction; CI: cardiac index; PCWP: pulmonary capillary wedge pressure. Duration: time elapsed from diagnosis.

Twenty two age, sex matched post-myocardial infarction patients (1-2 months after the acute event) without left ventricular dysfunction (LVEF $>50 \%$; all former smokers) served as controls. Demographic and cardiac function data of populations in study are shown in table 1.

\section{Cardiac function measurements}

$\mathrm{CHF}$ patients underwent right heart catheterization for evaluation of heart transplantation using a 7F Swan-Ganz balloon tipped thermodilution pulmonary artery catheter. Filling pressures were measured in the standard manner in supine position and were zero-referred to the level of the right atrium. Cardiac output $(\mathrm{CO})$ was measured by the standard thermodilution technique, and the average of three measurements was recorded. $\mathrm{CO}$ was normalized to a cardiac index (CI) after calculation of body surface area. LVEF was determined from left ventricular volumes obtained by 2Dechocardiography, according to Dodge formula.

\section{Pulmonary tests}

Spirometry was performed by means of a water spirometer in the seated posture, static lung volumes were assessed by means of helium dilution method (Biomedin, Padova, Italy). The predicted values were according to QUANJER [7]. Diffusing capacity for carbon monoxide (DıCo) was determined by the single-breath method (Biomedin, Padova, Italy).

An automated analyzer (ABL 500, Radiometer, Copenhagen, Denmark) was used to measure gases of arterialized blood from the ear lobe. The accuracy of this technique, in our laboratory [8] and elsewhere [9] has already been documented.

After spirometric testing while subjects breathed room air, breathing pattern and mouth occlusion pressure were evaluated. The subjects wearing a noseclip, were put in a comfortable seated position breathing through a mouthpiece on a circuit where inspiratory line was separated from the expiratory one by a two way valve (Jaeger GmbH, Hochberg, Germany). Airflow was measured with a Fleisch No. 3 pneumotachograph and the flow signal was integrated into volume. From the spirogram we derived breath-by breath time and volume components of the respiratory cycle: res- piratory frequency, tidal volume $(\mathrm{VT})$, minute ventilation $\left(\dot{\mathrm{V}}_{\mathrm{E}}\right)$, inspiratory time $(\mathrm{T} \mathrm{I})$, expiratory time $(\mathrm{TE})$, total respiratory time (Ttot), Ti/Ttot ratio and mean inspiratory flow $(\mathrm{VT} / \mathrm{TI})$. Mean values of 10 consecutive cycles were considered in data analysis.

The pressure developed at the mouth $0.1 \mathrm{~s}$ after the beginning of inspiration against an occluded airway (mouth occlusion pressure: $\mathrm{P}_{0.1}$ ) was recorded as previously described [10] during quiet breathing using a pressure transducer (Honeywell, $\pm 150 \mathrm{cmH}_{2} \mathrm{O}$, Freeport, Ill, USA) and the mean value of 5 determinations was kept into account. $\mathrm{P}_{0.1}$ was expressed both in absolute value $\left(\mathrm{cmH}_{2} \mathrm{O}\right)$ and as percentage of maximal inspiratory pressure (MIP) $\left(\mathrm{P}_{0.1} / \mathrm{MIP} \%\right)$ in order to normalize $\mathrm{P}_{0.1}$ for the individual differences in inspiratory muscle strength $[11,12]$. From $\mathrm{P}_{0.1}$ and mean inspiratory flow we calculated pulmonary impedence $\left(\mathrm{P}_{0.1} / \mathrm{VT}_{\mathrm{T}} / \mathrm{T}_{\mathrm{I}}\right)$.

Respiratory muscle strength was assessed by measuring maximal inspiratory and expiratory pressures (MIP and MEP respectively) breathing at the level of functional residual capacity (FRC) according to the method of BLACK and HyATT [13] using a differential pressure tranducer (Honeywell $\pm 200 \mathrm{cmH}_{2} \mathrm{O}$, Freeport, Ill. USA). The subjects comfortably seated, wearing a noseclip, performed maximal inspiratory and expiratory efforts starting from FRC against an obstructed mouthpiece with a small air leak to prevent glottis closure and a tap that allowed the airway to be closed. The subjects were verbally encouraged to achieve maximal strength. The determinations were repeated until 5 measurements varying by $<5 \%$ and sustained for at least 1 $\mathrm{s}$ were obtained; the best value achieved was considered in the data analysis.

All the respiratory function measurements were performed on the same day in random order allowing enough rest between each manouvre. Both cardiac and pulmonary function measurements were obtained when the patients were clinically stabilized. Pulmonary function measurements were performed within 10 days of cardiac function determinations. No change in therapeutics occurred between the cardiac and pulmonary function tests. The diagnosis of the severity of disease was blinded to the technician performing manoeuvres but not to a physician supervising them.

\section{Statistical analysis}

Data from patients with CHF and controls, and from patients with different NYHA classes were compared by one way analysis of variance ANOVA test, with a significant difference being inferred from $\mathrm{p}$ values $<0.05$. Pulmonary function data significantly different among the NYHA classes were compared to cardiac function indexes using regression analysis corrected for multiple comparison. Data are expressed as mean $( \pm \mathrm{SD})$.

The study was approved by the ethical committee of Clinica del Lavoro Foundation.

\section{Results}

Demographic and cardiac function data are shown in table 1. Control subjects were heavier. NYHA functional class III patients were slightly older than class II patients 
Table 2. - Ventilatory function and diffusion

\begin{tabular}{|c|c|c|c|c|c|c|c|c|}
\hline \multirow[b]{3}{*}{$\mathrm{VC} l$} & & & \multicolumn{6}{|c|}{$\mathrm{CHF}$} \\
\hline & \multicolumn{2}{|c|}{ Controls } & \multicolumn{2}{|c|}{ All } & \multicolumn{2}{|c|}{ NYHA II } & \multicolumn{2}{|c|}{ NYHA III } \\
\hline & 4.5 & $(0.8$ & 3.6 & $(0.8) * * *$ & 3.8 & $(0.7)$ & 3.2 & $(0.7)$ \\
\hline $\mathrm{FEV}_{1} l$ & 3.5 & $(0.7)$ & 2.8 & $(0.7) * * *$ & 2.9 & (0.6) & 2.6 & $(0.8)$ \\
\hline $\mathrm{MEF}_{25} \quad l \cdot \mathrm{s}^{-1}$ & 1.3 & $(0.7)$ & 1.1 & $(0.6)$ & 1.2 & $(0.5)$ & 1.0 & $(0.7)$ \\
\hline $\operatorname{MEF}_{50} l \cdot \mathrm{s}^{-1}$ & 4.6 & (2.1) & 4.0 & (1.8) & 4.2 & (1.5) & 3.6 & $(2.2)$ \\
\hline $\mathrm{FEV}_{1} / \mathrm{FVC} \quad \%$ & 76 & (9) & 78 & (7) & 78 & (7) & 78 & (7) \\
\hline TLC $l$ & 6.5 & (0.9) & 5.5 & $(1.0)^{* * *}$ & 5.8 & $(0.9)$ & 5.2 & $(0.9)$ \\
\hline $\mathrm{RV} l$ & 2.0 & $(0.4)$ & 1.9 & $(0.4)^{*}$ & 2.0 & $(0.5)$ & 1.9 & $(0.4)$ \\
\hline \multirow{2}{*}{$\begin{array}{ll}\text { DLCO } & \% \text { predicted } \\
& \mathrm{mmol} \cdot \mathrm{min} \cdot \mathrm{kPa}^{-1}\end{array}$} & 102 & (19) & 55 & $(17) * * *$ & 59 & (15) & 47 & (21) \\
\hline & 8.9 & (1.9) & 5.1 & $(1.5)^{* * *}$ & 5.5 & (1.2) & 4.3 & (1.9) \\
\hline \multirow{2}{*}{$\begin{array}{l}\% \text { predicted } \\
\mathrm{mmol} \cdot \mathrm{min} \cdot \mathrm{kPa}^{-1} \cdot l^{-1}\end{array}$} & 100 & (7) & 64 & $(16)^{* * *}$ & 69 & (16) & 55 & (14) \\
\hline & 1.54 & $(0.1)$ & 1.06 & $(0.2) * * *$ & 1.13 & $(0.2)$ & 0.90 & $(0.3)$ \\
\hline
\end{tabular}

****: significant difference between all $\mathrm{CHF}$ and controls $(\mathrm{p}<0.05,0.001) ; \uparrow$ : significant difference between NYHA classes $(\mathrm{p}<0.05)$; VC: vital capacity; $\mathrm{FEV}_{1}$ : forced expiratory volume in one second; FVC: expiratory forced vital capacity; $\mathrm{MEF}_{25}$ and $\mathrm{MEF}_{50}$ : maximal expiratory flows at $25 \%$ and $50 \%$ of expiratory FVC respectively; TLC: total lung capacity; RV: residual volume; DLCO: carbon monoxide diffusion capacity.

and, as expected, showed a trend towards a greater haemodynamic impairment.

Spirometric and diffusion data are summarized in table 2. CHF patients showed a slight but significant reduction in dynamic and static volumes. $\mathrm{MEF}_{25}$ and $\mathrm{MEF}_{50}$, indexes of small airway obstruction, were not significantly reduced either in the group with $\mathrm{CHF}$ or in the control group compared to normals. No difference was observed in $\mathrm{FEV}_{1} / \mathrm{FVC}$ ratio. Reduction in vital capacity (VC) and total lung capacity (TLC) was significantly greater in CHF patients of NYHA class III compared to class II. The eight patients

Table 3. - Arterial blood gases

\begin{tabular}{lcccc}
\hline & & \multicolumn{3}{c}{ CHF } \\
\cline { 3 - 5 } & Controls & All & NYHA II & NYHA III \\
\hline $\mathrm{pH}$ & $7.42(0.02)$ & $7.45(0.03)^{* * * *}$ & $7.44(0.02)$ & $7.46(0.03) \dagger$ \\
$\mathrm{PaCO}_{2} \mathrm{kPa}$ & $5.1(0.4)$ & $4.9(0.5)^{* * *}$ & $5(0.4)$ & $4.6(0.5) \dagger$ \\
$\mathrm{PaO}_{2} \mathrm{kPa}$ & $10.2(0.9)$ & $10.1(1)$ & $10.1(0.9)$ & $10.1(1)$ \\
$\mathrm{SaO}_{2} \%$ & $95(1)$ & $96(1)$ & $96(1)$ & $96(1)$ \\
$\mathrm{HCO}_{3} \mathrm{mM}$ & $25(1)$ & $26(2)$ & $26(2)$ & $25(3)$ \\
\hline
\end{tabular}

***: significant difference between all CHF and controls $(\mathrm{p}<0.001)$; $\dagger$, $\dagger \dagger$ : significant difference between NYHA classes $(\mathrm{p}<0.05$, 0.01 ); $\mathrm{PaO}_{2}$ and $\mathrm{PaCO}_{2}$ : arterial oxygen and carbon dioxide tensions showing roentgenographic signs of pleural effusions did not show a greater ventilatory resting pattern than the others, their mean VC and TLC being 3.42 (1.1) and 5.65 (1.4) $l$ respectively. A reduction in diffusion capacity, as assessed by measurement of DLCO, was also observed in CHF patients. When corrected for lung volume (KCO) diffusion capacity was still reduced although to a lesser degree (table 2). A significant positive relationship was found between DLCO and VC $(r=0.50, p<0.05)$ but not between DLCO and pulmonary capillary wedge pressure (PCWP).

Arterial blood gas values are shown in table $3 . \mathrm{PaCO}_{2}$ was lower in CHF patients compared to controls, and lower in NYHA III patients compared to the less severe CHF.

Breathing pattern is shown in table 4. $\dot{V}_{E}$ was higher than normal values both in controls and in study groups. CHF patients showed a significantly greater respiratory frequency than controls; $\mathrm{VT}_{\mathrm{T}}, \dot{\mathrm{V}}_{\mathrm{E}}$ and the mean inspiratory flow $(\mathrm{VT} / \mathrm{T} \mathrm{I})$, an index of neural drive, showed a trend toward an increase.

Results of respiratory muscle strength and mouth occlusion pressure are shown in table 5. In CHF patients MIP and MEP were slightly yet significantly reduced in comparison to controls. MIP, but not MEP, was reduced significantly more in NYHA class III than class II. $\mathrm{P}_{0.1}$ and $\mathrm{P}_{0.1} / \mathrm{MIP}$ ratio were significantly greater in $\mathrm{CHF}$ patients than in controls. $\mathrm{P}_{0.1} / \mathrm{VT}_{\mathrm{T}} / \mathrm{TI}$, an index of respiratory impedance

Table 4. - Ventilatory pattern

\begin{tabular}{|c|c|c|c|c|c|c|c|c|}
\hline \multirow[b]{3}{*}{$\begin{array}{ll}\mathrm{V}_{\mathrm{T}} & \mathrm{ml}\end{array}$} & & & \multicolumn{6}{|c|}{$\mathrm{CHF}$} \\
\hline & \multicolumn{2}{|c|}{ Controls } & \multicolumn{2}{|c|}{ All } & \multicolumn{2}{|c|}{ NYHA II } & \multicolumn{2}{|c|}{ NYHA III } \\
\hline & 920 & $(155)$ & 927 & (243) & 908 & (191) & 949 & (297) \\
\hline $\begin{array}{l}\text { Respiratory } \\
\text { frequency bpm }\end{array}$ & 16 & (4) & 18 & $(5)^{*}$ & 19 & (4) & 18 & (5) \\
\hline$\dot{\mathrm{V}}_{\mathrm{E}} l \cdot \mathrm{min}^{-1}$ & 14.9 & (4.1) & 16.7 & $(4.8)$ & 16.9 & $(4.3)$ & 16.6 & $(5.5)$ \\
\hline TI/Ttot \% & 43 & (5) & 44 & (4) & 43 & (4) & 44 & (4) \\
\hline $\mathrm{V}_{\mathrm{T}} / \mathrm{T}_{\mathrm{I}} \mathrm{ml} / \mathrm{sec}^{-1}$ & 568 & (147) & 639 & (184) & 654 & (168) & 622 & (205) \\
\hline
\end{tabular}

*: significant difference between all CHF and controls $(p<0.05)$. There were no significant differences $(p>0.05)$ between patients with CHF. VT: tidal volume; $\dot{V}_{\mathrm{E}}$ : minute ventilation; Tr: inspiratory time; Ttot: total respiratory time; VT/Tr: mean inspiratory flow; bpm: breaths per minute. 
Table 5. - Respiratory muscle strength and ventilatory drive

\begin{tabular}{|c|c|c|c|c|c|c|c|c|}
\hline \multirow[b]{3}{*}{$\mathrm{MIP} \mathrm{cmH}_{2} \mathrm{O}$} & & & \multicolumn{6}{|c|}{$\mathrm{CHF}$} \\
\hline & \multicolumn{2}{|c|}{ Controls } & \multicolumn{2}{|c|}{ All } & \multicolumn{2}{|c|}{ NYHA II } & \multicolumn{2}{|c|}{ NYHA III } \\
\hline & 104 & $(28)$ & 79 & $(27)^{* *}$ & 88 & (27) & 70 & $(24)++\dagger$ \\
\hline $\mathrm{MEP} \mathrm{cmH}_{2} \mathrm{O}$ & 142 & (33) & 111 & $(32)^{* *}$ & 118 & (30) & 103 & $(34)++$ \\
\hline $\mathrm{P}_{0.1} \quad \mathrm{cmH}_{2} \mathrm{O}$ & 1.4 & $(0.6)$ & 1.86 & $(0.7)^{* *}$ & 1.8 & $(0.7)$ & 1.9 & $(0.9)++$ \\
\hline $\mathrm{P}_{0.1} / \mathrm{MIP} \%$ & 1.4 & $(0.7)$ & 2.7 & $(1.4)^{* *}$ & 2.3 & $(1.3)$ & 3.0 & $(1.5)++$ \\
\hline $\mathrm{P}_{01} / \mathrm{V}_{\mathrm{T}} / \mathrm{TI}_{\mathrm{I}} \quad \mathrm{cmH}_{2} \mathrm{O} \cdot l^{-1} \cdot \mathrm{s}^{-1}$ & 2.4 & $(0.9)$ & 3.0 & $(1.4)^{* *}$ & 2.8 & $(1.2)$ & 3.3 & $(1.6)+$ \\
\hline
\end{tabular}

*: significant difference between all $\mathrm{CHF}$ and controls $(\mathrm{p}<0.01)$; + : significant difference between NYHA classes $(\mathrm{p}<0.05) ;+,++$ : significant difference between NYHA class III and controls ( $<<0.05,<0.01$ ); MIP: maximal static inspiratory pressure; MEP: maximal static expiratory pressure; $\mathrm{P}_{0.1}$ : mouth occlusion pressure.

[14], was significantly greater in CHF patients of NYHA class III than in controls.

Neither PCWP, nor CI nor LVEF significantly correlated with ventilatory drive, respiratory muscle strength indexes or other respiratory functional parameters. Regression analysis showed a good relationship only between MIP and MEP $(\mathrm{r}=0.70, \mathrm{p}<0.0001)$.

\section{Discussion}

This study indicates that $\mathrm{P}_{0.1}$ and $\mathrm{P}_{0.1} / \mathrm{MIP}$ ratio, indexes of neural drive to respiratory muscles, are increased in resting CHF patients compared to controls while breathing pattern shows only a slight increase in respiratory frequency. Furthermore, this study confirms and extends on a larger number of patients the previously observed reduction in respiratory muscle strength [5]. A mild restrictive ventilatory defect and abnormality in diffusion were also confirmed in these patients.

\section{Ventilatory function and diffusion capacity}

Our patients showed a reduction in both forced vital capacity (FVC) and forced expiratory volume in one second $\left(\mathrm{FEV}_{1}\right)$ a fact which can be attributed to pulmonary congestion and oedema, and a reduction in diffusion as assessed by Duco. Dlco impairment, as in our CHF patients, either alone or combined with ventilatory restriction and/or obstruction, was found in patients who underwent pulmonary function testing as part of an evaluation for possible heart transplantation [3, 4]. Several explanations have been suggested for the high prevalence of diffusion capacity impairment, among which is the smoking habit of the patients. All but two patients and all control subjects in our study were current or former smokers: $\mathrm{FEV}_{1} / \mathrm{FVC}$ ratio was $<80 \%$ and $\mathrm{MEF}_{25}$ and $\mathrm{MEF}_{50}$ were reduced in both groups, an observation which might suggest a slight obstructive defect which is well known in smokers. Restriction per se might explain the reduction in diffusion capacity since, at variance with other studies [3, 4], a slight but significant relationship between DLCO and VC was found in our patients. Furthermore, correction of Duco for lung volume, $\mathrm{KCO}$, showed that diffusion was less compromised than when assessed by Duco alone. In other studies [3, 4] a positive correlation of PCWP, but not CI nor LVEF, with DLCO has been found. This observation might support chronic passive congestion as a mechanism of reduced Deco [15]. Our data partially support this hypothesis as nearly all patients had chest roentgenographic signs attributable to pulmonary vascular congestion. However, regression analysis showed no significant relationship between PCWP and DLCO. Recurrent pulmonary emboli, for which these patients have been considered to be at risk, have been also hypothesized [16].

\section{Neural drive and breathing pattern}

All the aforementioned mechanisms, particularily pulmonary congestion, might be considered, at least theoretically, to explain the increase in central neural drive to inspiratory muscles as assessed by $\mathrm{P}_{0.1}$. Mouth occlusion pressure is an index that reflects both neural drive to, and the resulting force output of, the inspiratory muscles [10]. Although $\mathrm{P}_{0.1}$ is used as an index of neural output to inspiratory muscles in normal subjects, in patients with reduction in inspiratory muscle strength, absolute values of $\mathrm{P}_{0.1}$ may underestimate the effective neural drive $[17,18] . \mathrm{P}_{0.1} / \mathrm{MIP}$ ratio is used as an index of central respiratory output normalized for inspiratory muscle strength [11, 12]. In the present study both $\mathrm{P}_{0.1}$ and $\mathrm{P}_{0.1} / \mathrm{MIP}$ ratio were significantly greater in CHF patients than in the control group, indicating an increased neural drive to inspiratory muscles in patients with CHF. $\mathrm{P}_{0.1} / \mathrm{VT} / \mathrm{TI}$ ratio, an index of pulmonary impedance [14], was significantly greater in CHF patients of NYHA class III than in controls.

To our knowledge, this is the first report of measurement of respiratory drive, by $\mathrm{P}_{0.1}$ in resting $\mathrm{CHF}$ patients. Sullivan et al. [19], studied ambulatory patients with CHF of similar severity and found that, compared to normal controls, ventilation and the ratio of ventilation to $\mathrm{CO}_{2}$ production $\left(\dot{\mathrm{V}} \mathrm{E} / \mathrm{V}_{\mathrm{CO}}\right)$ were elevated at rest and during exercise, suggesting that "neurohumoral ventilatory control mechanisms are intact". Their patients showed an increase in the ratio of pulmonary dead space to tidal volume $\left(\mathrm{VD}_{\mathrm{D}} / \mathrm{VT}\right)$ both at rest and during exercise. Neither $\mathrm{VD}_{\mathrm{D}} / \mathrm{V}_{\mathrm{T}}$ nor $\dot{\mathrm{V}} \mathrm{CO}_{2}$ were measured in our study and the absence of these measurements make it impossible to determine whether the trend toward increased $\dot{\mathrm{V}}_{\mathrm{E}}$, breathing frequency and 
$\mathrm{P}_{0.1}$ were exclusively related to increased ventilatory drive or whether it was also related to increased dead space or metabolic rate. The decreased $\mathrm{PaCO}_{2}$ in the study group may indirectly support an increase in ventilatory drive and/or an increased metabolic rate. Both our patients and controls showed high levels of minute ventilation, mainly due to an increase in $\mathrm{V}_{\mathrm{T}}$. A mouthpiece may affect normal resting ventilation, mainly increasing $\mathrm{V}_{\mathrm{T}}$ and, thus, the measurement of ventilation would have been better performed noninvasively [20, 21]. Therefore, this aspect of our results should be considered preliminary and treated with caution.

In comparison to patients with normal values of PCWP, reduced levels of $\mathrm{PaCO}_{2}$ and increased $\mathrm{pH}$ were found by BRADLEY et al. [22] in a small number of patients with high values of PCWP. These were explained by the effect of a great degree of pulmonary congestion secondary to a high left ventricular diastolic pressure. Again, in spite of the fact that most of our patients showed roentgenographic signs of pulmonary vascular congestion, we did not find any significant relationship between PCWP and $\mathrm{P}_{0.1}$ nor $\mathrm{P}_{01} / \mathrm{MIP}$ ratio. This might be due to the fact that most of the patients in our population had elevated PCWP which may disguise any relationship between PCWP and other variables. Theoretically, stimulation of pulmonary receptors by a raised PCWP may heighten central neural drive [23]. Passive engorgement of pulmonary vessels has been reported to have only a minor effect in decreasing VC and lung compliance, but to increase $\dot{\mathrm{V}}_{\mathrm{E}}$ at rest and at all levels of activity leading to unnecessary hypocapnia [24].

\section{Respiratory muscle strength}

Although the elevated $\mathrm{P}_{0.1}$ we found would be expected in the setting of a higher minute ventilation, it has been hypothesized that the neural drive could be increased in response to respiratory muscle weakness [25]. Respiratory muscle receptors, able to transmit sensory information related to muscle tension (tendon organs), can modify respiratory drive [26] and they could be involved in this compensating reflex. The present results showing a reduction in MIP and MEP are consistent with the above hypothesis. The reduction in MIP and MEP observed in our patients extends the results by HAMMOND et al. [5]. In their patients, as in ours, MIP and MEP seemed to be comparably impaired. They found that the handgrip force was less dramatically reduced suggesting selective respiratory muscle weakness. MANCINI et al. [27] found a slight reduction in MIP and no change in MEP. The reduction in MIP and MEP of our patients compared to controls were less severe than in Hammond's study [5]. Although the MIP and MEP values of controls were similar in both studies, this difference might be ascribed to differences in methods, motivation of patients or other. Although respiratory muscle strength was not related to any of the measured cardiac parameters, particularly LVEF and CI, the observed reduction in MIP and MEP was more pronounced in more severe CHF patients according to NYHA classes. Patients of Hammond's study [5] were described according to LVEF and no information was given on functional classes, although being ambulatory outpatients it is unlikely that they had a greater functional impairment than our patients.

\section{Clinical implications of the study}

Several studies [19, 28, 29] in patients with CHF have failed to demonstrate a direct relationship between dyspnoea and PCWP both at rest and with exercise. The increase in neural ventilatory drive as assessed by $\mathrm{P}_{0.1}$ and $\mathrm{P}_{0.1} / \mathrm{MIP}$ might contribute to the level of dyspnoea that these patients often suffer from [30]. Furthermore the reduction in inspiratory muscle strength may contribute to dyspnoea by increasing the ratio of the pressure developed at the mouth during tidal breathing to the maximal inspiratory pressure (Pm/MIP) which has been suggested to contribute to the sensation of dyspnoea [31]. The relationship of these resting measurements to the mechanisms of dyspnoea on exercise in these patients remains to be elucidated. Recently MCPARLAND et al. [32], in nine chronic heart failure patients, have found reduced inspiratory and expiratory muscle strength, both being significantly correlated with dyspnoea during daily activity.

The importance of assessing the pulmonary function abnormalities in patients with chronic congestive heart failure is highlighted by the fact that many are currently candidates for cardiac transplantation and that post-transplantation outcome may be influenced by the level of pretransplant pulmonary function. Furthermore respiratory muscle weakness, if present, may negatively influence the outcome of surgical intervention and suggests the need to perform inspiratory muscle training before surgery [33].

In conclusion our study shows that $\mathrm{P}_{0.1}$ and $\mathrm{P}_{0.1} / \mathrm{MIP} \%$, which are considered indexes of neural ventilatory drive, are increased in resting CHF patients of different severity. The mechanisms leading to this increase and the relationships with dyspnoea, if any, remain speculative.

\section{References}

1. Light RW, George RB. - Serial pulmonary function in patients with acute heart failure. Arch Intern Med 1983; 143: 429-433.

2. Ries AL, Gregoratos G, Friedman PJ, Clausen JL. - Pulmonary function tests in the detection of left heart failure: correlation with pulmonary artery wedge pressure. Respiration 1986; 49: 241-250.

3. Wright RS, Levine MS, Bellamy PE, et al. - Ventilatory and diffusion abnormalities in potential heart transplant recipients. Chest 1990; 98: 816-820.

4. Naum CC, Sciurba FC, Rogers RM. - Pulmonary function abnormalities in chronic severe cardiomyopathy preceding cardiac transplantation. Am Rev Respir Dis 1992; 145: 1334-1338.

5. Hammond MD, Bauer KA, Sharp JT, Rocha RD. Respiratory muscle strength in congestive heart failure. Chest 1990; 98: 1091-1094.

6. Criteria Committee of the New York Association, Kossman $\mathrm{CE}$, (chairman). Diseases of the heart and blood vessels: nomenclature and criteria for diagnosis. Boston, Little Brown \& co., 1964; p 112.

7. Quanjer PH. - Working Party on "Standardization of lung function test". Bull Eur Physiopathol Respir 1983; 19 (Supp 15): 7-10.

8. Majani U, Dacosto E, Negri A, Rampulla C. - L'emogasanalisi arteriosa. Rass patol App Resp 1988; 3: 26-33. 
9. Siggard D, Andersen N. - Acid base and blood gases parameters: arterial or capillary blood? Scand J Clin Invest 1968; 4: 289-292.

10. Whitelaw WA, Derenne JP, Milic-Emili J. - Occlusion pressure as a measure of respiratory center output in conscious man. Resp Physiol 1975; 23: 181-199.

11. Peterson DD, Pack AL, Silage DA, Fishman AP. - Effects of ageing on ventilatory and occlusion pressure responses to hypoxia and hypercpania. Am Rev Respir Dis 1981; 124: 387-391.

12. Gorini M, Ginanni R, Spinelli A, Duranti R, Andreotti L, Scano G. - Inspiratory muscle strength and respiratory drive in patients with rheumatoid arthritis. Am Rev Respir Dis 1990; 142: 289-294.

13. Black L, Hyatt R. - Maximal airway pressures: normal values and relationship to age and sex. Am Rev Respir Dis 1969; 99: 696-702.

14. Hussain SNA, Pardy RL, Dempsey JA. - Mechanical impedance as determinant of inspiratory neural drive during exercise in humans. J Appl Physiol 1985; 59: 365-375.

15. Millard M. Lung, pleura and mediastinum. - In: Anderson WAD, Kissane JM eds. Pathology, St Louis, CV Mosby, 1977: 1038-1159.

16. Roberts WC, Siegel RJ, Mc Manus BM. - Idiopathic dilated cardiomyopathy: analysis of 152 necropsy patients. Am J Cardiol 1987; 60: 1340-1355.

17. Sharp JT, Hyatt RE. - Mechanical and electrical properties of respiratory muscles. In: Macklem PT, Mead J eds. Handbook of physiology: The respiratory system: Mechanics of breathing (sec 3, vol 3, pt 2). Bethesda, Md: American Physiological Society, 1986: 389-414.

18. DeTroyer A, Pride NB. - The respiratory system in neuro-muscular disorders. In: Roussos C, Macklem PT, eds. The Thorax. New York, Dekker, 1985; 1089-1121.

19. Sullivan M, Higginbotham M, Cobb F. - Increased exercise ventilation in patients with chronic heart failure: intact ventilatory control despite hemodynamic and pulmonary abnormalities. Circulation 1988; 77: 552-559.

20. Gilbert R, Auchincloss IH Jr, Brodsky J, Boden W. Changes in tidal volume, frequency, and ventilation induced by their measurement. J Appl Physiol 1972; 33: 252-254.

21. Askanazi J, Silverberg PA, Foster RJ, Hyman AI, Milic
Emili J, Kinney JM. - Effects of respiratory apparatus on breathing pattern. J Appl Physiol 1980; 48: 577-580.

22. Bradley TD, Holloway RM, McLaughlin PR, Ross BL, Walters J, Liu PP. - Cardiac output response to continuous positive airway pressure in congestive heart failure. $A m$ Rev Respir Dis 1992: 145: 377-382.

23. Paintal A. - A mechanism of stimulation of type $\mathrm{J}$ pulmonary receptors. J Physiol 1969; 203: 511-532.

24. Reed JW, Ablett M, Cotes JE. - Ventilatory responses to exercises and to carbon dioxide in mitral stenosis before and after valvulotomy: causes of tachypneoa. Clin Sci Mol Med 1978; 54: 9-15.

25. Begin R, Bureau MA, Lupien L, Lemieux B. - Control of breathing in Duchenne's muscular dystrophy. Am J Med 1980; 69: 227-234.

26. Shannon R. - Reflexes from respiratory muscles and costovertebral joints. In: Cherniack NS, Widdicombe JG, eds. Handbook of physiology: the respiratory system. Vol II. Control of breathing. Part I. Bethesda: American Physiological Society, 1986: 431-447.

27. Mancini DM, Ferraro N, Nazzaro D, Chance B, Wilson JR. - Respiratory muscle deoxygenation during exercise in patients with heart failure demonstrated with near-infrared spectroscopy. J Am Coll Cardiol 1991; 18: 492-498.

28. Fink L, Wilson J, Schwartz D. - Relation between hemodynamic and ventilatory responses in determining exercise capac ity in severe congestive heart failure. Am J Cardiol 1986; 57: 249-253.

29. Mancini DM, Henson D, LaManca J, Levine S. - Respiratory muscle function and dyspnea in patients with chronic congestive heart failure. Circulation 1992; 86: 909-918.

30. Killian KJ, Gandevia SC, Summers E, Campbell EJM. Effect of increased lung volume on perception of breathlessness, effort and tension. J Appl Physiol 1984; 57: 686-691.

31. Killian K, Jones N. - Respiratory muscles and dyspnea. Clin Chest Med 1988; 9: 237-248.

32. McParland C, Krishnan B, Wang Y, Gallagher CG. Inspiratory muscle weakness and dyspnea in chronic heart failure. Am Rev Respir Dis 1992; 148: 467-472.

33. Rampulla C, Ambrosino N. - Inspiratory muscle training and rest. Eur Respir Rev 1991, 1: 490-497. 